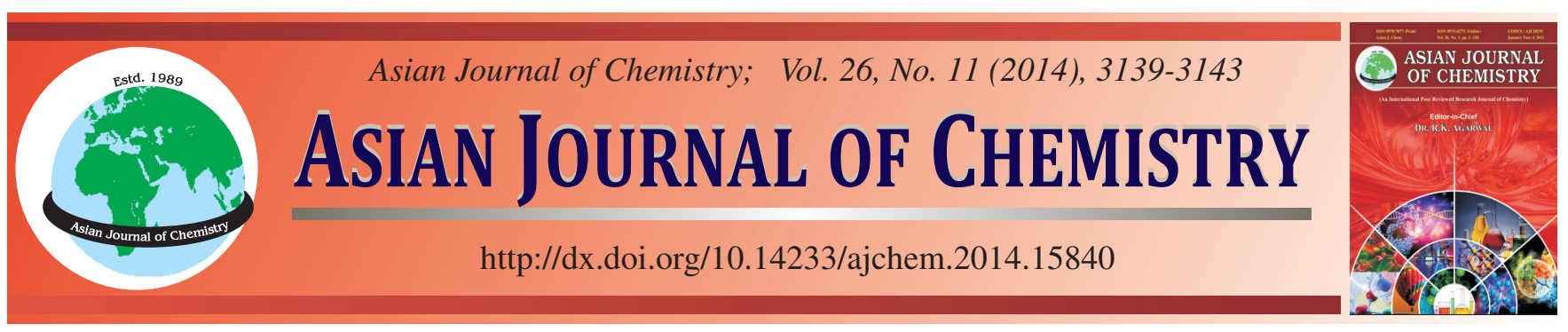

\title{
Synthesis and Nematicidal Bioevaluation of Substituted $2 H$-1-Benzopyrane-2-ones and their Carbamate Derivatives Against Root-Knot Nematode (Meloidogyne javanica)
}

\author{
Sumona Kumari, Rajvir Singh ${ }^{*}$, Anil Kumar and R.K. Walia
}

Department of Chemistry \& Physics, CCS Haryana Agricultural University, Hisar-125 004, India

*Corresponding author: E-mail: rajvir@hau.ernet.in

Received: 29 May 2013;

Accepted: 15 October 2013;

Published online: 25 May 2014;

AJC-15200

Synthesis of 7-hydroxy-4,5-methyl/7-hydroxy-4-methyl/7,8-dihydroxy-4-methyl/6-chloro-7-hydroxy-4-methyl-2H-1-benzopyrane-2-ones (VI-IX) have been carried out by Pechmann reaction. The condensation of synthesized $2 H$-1-benzopyran-2-ones (VI-X) with phenyl isocyanate (XI) gave 4,5-methyl/4-methyl/4-methyl/6-chloro-4-methyl-2-oxo-2H-benzopyran-7yl/7,8-diyl/4-yl/phenyl carbamates (XIIXVI). The synthesized compounds were characterized on the basis of analytical and spectral data. All the compounds were evaluated for their nematicidal activity in vitro against second stage juveniles $\left(J_{2}\right)$ of root-knot nematode (Meloidogyne javanica).

Keywords: Substituted-2H-1-benzopyran-2-one, Carbamate, Nematicidal activity, Root-knot nematode, Meloidogyne javanica.

ᄂ _ - - - - - - - - - - - - - - - - - - - - - - - -

\section{INTRODUCTION}

2H-1-benzopyran-2-ones are versatile intermediate for the synthesis of various organic compounds. They also exhibit diverse biological activities ${ }^{1-3}$. In present study, we have utilized hydroxyl substituted $2 \mathrm{H}$-1-benzopyran-2-ones as starting material for the synthesis of carbamates. Carbamates are derivatives of carbamic acid, $\mathrm{HOC}(\mathrm{O}) \mathrm{NH}_{2}$ and are widely used as insecticides. These were originally extracted from the calabar bean, which grows in west Africa. Physostigmine, a methyl carbamate ester was isolated and characterized from the extract of this bean ${ }^{4}$. The synthesis of carbamates are of particular interest due to their usefulness as agrochemicals like herbicides, fungicides and antimicrobial agents ${ }^{5}$. Carbamates are also used in pharmaceuticals industry as drug intermediates ${ }^{6}$. They are generally not persistent in the environment for long time.

Among different pests, the plant parasitic nematodes cause significant losses in major crops like oil seed, cereals, pulses, sugarcane, fruit crops and vegetables. In addition to directly causing crop losses, nematodes can vector many plant viruses. Many species of nematodes exist and they attack an enormous variety of plant species. The Meloidogyne spp. of root-knot nematodes are economically important, since these are polyphagus, vastly distributed and sedentary endoparasites in nature. Among Meloidogyne sp., Meloidogyne javanica is most common species of root knot nematodes. Carbamates are commonly used due to their chemical stability towards acids, bases and hydrogenation? ${ }^{7}$ Carbamates inhibit acetyl choli- nesterase $(\mathrm{AChE})$ in the nervous system and thereby, disrupt nervous transmission at that location ${ }^{8}$.

The development of synthetic pesticides revolutionized pest management in agriculture. In view of the diverse biological activities shown by carbamates, their importance as agrochemicals and as a part of our research ${ }^{9-11}$, the synthesis and nematicidal activity of substituted 2-oxo- $2 H$-1-benzopyran7-yl/7,8-diyl/4-yl phenyl carbamates have been carried out and results are reported in this paper.

\section{EXPERIMENTAL}

The melting points were determined in open capillaries on a Ganson electrical melting point apparatus. Homogeneity of the compounds was routinely checked on silica gel-G TLC plates using ethyl acetate:hexane (3:7) as irrigant. IR spectra were recorded on Perkin Elmer FTIR spectrophotometer. The NMR spectra were recorded on Bruker AC-400-F (400 MHz) NMR spectrophotometer in $\mathrm{CDCl}_{3}$ or DMSO- $d_{6}$ using tetramethylsilane (TMS) as internal reference. The chemical shift values are expressed in $\delta$ (ppm) units while $J$ values in $\mathrm{Hz}$ and are compatible with the assigned structures. The elemental analyses were within $\pm 0.4 \%$ of that of evaluated values. Only those spectral data have been mentioned which have a direct bearing on the assignment of the structures and are discussed here.

7-Hydroxy-4,5-dimethyl-2H-1-benzopyran-2-one (VI): A mixture of orcinol (I, $2.48 \mathrm{~g}, 20 \mathrm{mmol}$ ) and benzyl acetoacetate $(\mathbf{V}, 3.84 \mathrm{~g}, 20 \mathrm{mmol})$, was added portion wise to $\mathrm{H}_{2} \mathrm{SO}_{4}$ (30 mL, $73 \%$ ) with constant stirring in cold condition. The 
reaction mixture was left overnight and mixed with crushed ice to get a solid product, filtered, dried and crystallized from methanol to get VI, yield $80 \%$, m.p. $253-255^{\circ} \mathrm{C}$ (lit. 251-253 $\left.{ }^{\circ} \mathrm{C}\right)^{12}$. IR (nujol, $v_{\max }, \mathrm{cm}^{-1}$ ): $3390(\mathrm{OH}), 1685(\mathrm{C}=\mathrm{O}), 1365$

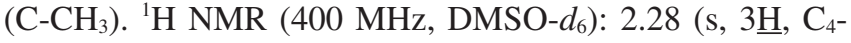
$\left.\mathrm{C}_{3}\right) ; 2.56\left(\mathrm{~s}, 3 \underline{\mathrm{H}}, \mathrm{C}_{5}-\mathrm{CH}_{3}\right) ; 5.91\left(\mathrm{~s}, 1 \mathrm{H}, \mathrm{C}_{3}-\mathrm{H}\right) ; 6.51\left(\mathrm{~s}, 1 \mathrm{H}, \mathrm{C}_{8}-\right.$ $\mathrm{H})$; 6.56 (s, $\left.1 \underline{\mathrm{H}}, \mathrm{C}_{6}-\underline{\mathrm{H}}\right)$. Analysis found: C, 69.61; H, $5.29 \%$; $\mathrm{C}_{11} \mathrm{H}_{10} \mathrm{O}_{3}$ Required: C, 69.46; H, $5.30 \%$.

Compounds VII-IX were prepared similarly from II-IV and $\mathbf{V}$ respectively.

7-Hydroxy-4-methyl-2H-1-benzopyran-2-one (VII): Yield $78 \%$, m.p. $183{ }^{\circ} \mathrm{C}$ (lit. $185-186{ }^{\circ} \mathrm{C}$ ) ${ }^{13}$. IR (nujol, $v_{\max }$, $\left.\mathrm{cm}^{-1}\right)$ : $3400(\mathrm{OH}), 1671(\mathrm{C}=\mathrm{O}), 1390\left(\mathrm{C}-\mathrm{CH}_{3}\right) .{ }^{1} \mathrm{H}$ NMR $(400$ $\left.\mathrm{MHz}, \mathrm{DMSO}-d_{6}\right): 2.38$ (s, 3프, C4- $\left.\mathrm{CH}_{3}\right) ; 6.03\left(\mathrm{~s}, 1 \underline{\mathrm{H}}, \mathrm{C}_{3}-\underline{\mathrm{H}}\right)$; $6.71\left(\mathrm{~s}, 1 \underline{\mathrm{H}}, \mathrm{C}_{8}-\underline{\mathrm{H}}\right) ; 6.80\left(\mathrm{~d}, J=7.5 \mathrm{~Hz}, 1 \underline{\mathrm{H}}, \mathrm{C}_{6}-\underline{\mathrm{H}}\right) ; 7.48$ (d, $J=$ $\left.7.5 \mathrm{~Hz}, 1 \underline{\mathrm{H}}, \mathrm{C}_{5}-\underline{\mathrm{H}}\right)$. Analysis found: $\mathrm{C}, 68.12 ; \mathrm{H}, 4.55 \%$. $\mathrm{C}_{10} \mathrm{H}_{8} \mathrm{O}_{3}$ Required: C, 68.18; $\mathrm{H}, 4.58 \%$.

7,8-Dihydroxy-4-methyl-2H-1-benzopyran-2-one (VIII): Yield $78 \%$, m.p. $239^{\circ} \mathrm{C}$ (lit.235-237 ${ }^{\circ} \mathrm{C}$ ) ${ }^{14}$. IR (nujol, $\left.v_{\max }, \mathrm{cm}^{-1}\right): 3231(\mathrm{OH}), 1651(\mathrm{C}=\mathrm{O}), 1371\left(\mathrm{C}-\mathrm{CH}_{3}\right) .{ }^{1} \mathrm{HNMR}$

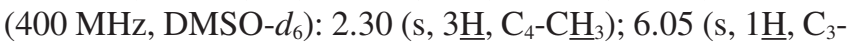
$\underline{\mathrm{H}})$; 6.95-7.75 (m, 4프, Ar- $\underline{\mathrm{H}})$. Analysis found: C, 62.23; H, $4.22 \% . \mathrm{C}_{10} \mathrm{H}_{8} \mathrm{O}_{4}$ Required: C, 62.50; H, $4.20 \%$.

6-Chloro-7-hydroxy-4-methyl- $2 \mathrm{H}$-1-benzopyran-2one (IX): Yield $82 \%$, m.p. $268-270^{\circ} \mathrm{C}$. IR (nujol, $v_{\max }, \mathrm{cm}^{-1}$ ): $3370(\mathrm{OH}), 1678(\mathrm{C}=\mathrm{O}), 844(\mathrm{C}-\mathrm{Cl}), 1605(\mathrm{C}=\mathrm{C}), 1390(\mathrm{C}-$ $\left.\mathrm{CH}_{3}\right){ }^{1} \mathrm{H}$ NMR $\left(400 \mathrm{MHz}, \mathrm{DMSO}-d_{6}\right): 2.37\left(\mathrm{~s}, 1 \underline{\mathrm{H}}, \mathrm{C}_{4}-\mathrm{CH}_{3}\right)$;

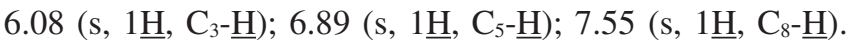
Analysis found: $\mathrm{C}, 57.36 ; \mathrm{H}, 3.37 . \mathrm{C}_{10} \mathrm{H}_{7} \mathrm{O}_{3} \mathrm{Cl}$ Required: $\mathrm{C}$, $57.03 ; \mathrm{H}, 3.35$.

4-Hydroxy $\mathbf{2 H}$-1-benzopyran-2-one $(\mathrm{X})^{\mathbf{1 5}}$ : A mixture of malonic acid monophenyl ester $(180 \mathrm{mg}, 1 \mathrm{mmol})$ and Eaton's reagent $(3 \mathrm{~mL})$ was stirred at $70^{\circ} \mathrm{C}$ for $1 \mathrm{~h}$ and then water was added to this mixture while stirring vigorously. Completion of the reaction was monitored by TLC. The precipitate was filtered, washed with water and dried to give a solid. It was recrystallized from ethanol to afford $\mathbf{X}$. Yield $80 \%$, m.p. 209$210{ }^{\circ} \mathrm{C}$. IR (nujol, $v_{\max }, \mathrm{cm}^{-1}$ ): $3380(\mathrm{OH}), 1680(\mathrm{C}=\mathrm{O}) .{ }^{1} \mathrm{H}$ NMR (400 MHz, DMSO- $\left.d_{6}\right): 5.56$ (s, $\left.1 \underline{\mathrm{H}}, \mathrm{C}_{3}-\underline{\mathrm{H}}\right)$; 7.19-7.25 $(\mathrm{m}, 2 \underline{\mathrm{H}}) ; 7.48-7.53(\mathrm{~m}, 1 \underline{\mathrm{H}}) ; 7.72(\mathrm{~d}, 1 \underline{\mathrm{H}}, \mathrm{J}=8.0 \mathrm{~Hz}) ; 11.95(\mathrm{~s}$, $1 \underline{\mathrm{H}}, \mathrm{OH})$. Analysis found: $\mathrm{C}, 66.17 ; \mathrm{H}, 3.76 \% . \mathrm{C}_{9} \mathrm{H}_{6} \mathrm{O}_{3}$ Required : C, 66.67; H, $3.73 \%$.

4,5-Dimethyl-2-oxo-2H-1-benzopyran-7-yl phenylcarbamate (XII): A mixture of 7-hydroxy-4,5-dimethyl-2H1-benzopyran-2-one (VI, $3.80 \mathrm{~g}, 20 \mathrm{mmol}$ ) and phenylisocyanate (XI, $2.38 \mathrm{~g}, 20 \mathrm{mmol})$ in dry benzene $(20 \mathrm{~mL})$ was refluxed for $12 \mathrm{~h}$ on steam bath. Completion of the reaction was monitored by TLC. It was then concentrated under vacuum, to give solid residue which was crystallized from methanol to afford XII, Yield: $78 \%$, m.p. $218-220^{\circ} \mathrm{C}$. IR (nujol, $v_{\max }, \mathrm{cm}^{-1}$ ): $3370(\mathrm{NH}), 1690$ (NH-CO), 1680 (C=O). ${ }^{1} \mathrm{H}$ NMR (400 MHz, DMSO-d $\left.d_{6}\right): 2.29$ (s, 3프, $\left.\mathrm{C}_{4}-\mathrm{CH}_{3}\right) ; 2.55\left(\mathrm{~s}, 3 \underline{\mathrm{H}}, \mathrm{C}_{5}-\mathrm{CH}_{3}\right) ; 5.93$ $\left(\mathrm{s}, 1 \underline{\mathrm{H}}, \mathrm{C}_{3}-\underline{\mathrm{H}}\right) 6.53$ (s, $\left.1 \underline{\mathrm{H}}, \mathrm{C}_{6}-\underline{\mathrm{H}}\right) ; 6.92$ (s, $\left.\underline{1} \underline{\mathrm{H}}, \mathrm{C}_{8}-\underline{\mathrm{H}}\right) ; 7.22-$ 7.46 (m, $5 \underline{\mathrm{H}}, \mathrm{Ar}-\underline{\mathrm{H}}) ; 8.50$ (s, $\underline{\mathrm{H}}, \mathrm{N} \underline{\mathrm{H}})$. Analysis found: $\mathrm{C}, 69.54$; $\mathrm{H}, 4.82 ; \mathrm{N}, 4.51 \% . \mathrm{C}_{18} \mathrm{H}_{15} \mathrm{NO}_{4}$ Required: C, 69.89; H, 4.89; $\mathrm{N}, 4.53 \%$.

Other compounds XIII-XVI were prepared similarly from VII-X and XI respectively.
4-Methyl-2-oxo-2H-1-benzopyran-7-yl phenylcarbamate (XIII): Yield $76 \%$, m.p. $138-140{ }^{\circ} \mathrm{C}$. IR (nujol, $v_{\max }$, $\mathrm{cm}^{-1}$ ): $3400(\mathrm{NH}), 1695$ (NH-CO), $1680(\mathrm{C}=\mathrm{O}) .{ }^{1} \mathrm{H}$ NMR (400 MHz, DMSO-d $d_{6}$ ): 2.45 (s, 3H, C $\left.{ }_{4}-\mathrm{CH}_{3}\right) ; 5.94$ (s, $1 \underline{\mathrm{H}}, \mathrm{C}_{3}-\underline{\mathrm{H}}$ ); 6.89 (s, $\left.1 \underline{\mathrm{H}}, \mathrm{C}_{8}-\underline{\mathrm{H}}\right) ; 6.97$ (s, $\left.1 \underline{\mathrm{H}}, \mathrm{C}_{6}-\underline{\mathrm{H}}\right) ; 6.92-7.48$ (m, 5므, Ar$\underline{\mathrm{H}}) ; 8.49$ (s, $1 \underline{\mathrm{H}}, \mathrm{N} \underline{\mathrm{H}})$. Analysis found: $\mathrm{C}, 69.34 ; \mathrm{H}, 4.40 ; \mathrm{N}$, $4.69 \% ; \mathrm{C}_{17} \mathrm{H}_{13} \mathrm{NO}_{4}$ Required: $\mathrm{C}, 69.15 ; \mathrm{H}, 4.44 ; \mathrm{N}, 4.74 \%$.

4-Methyl-2-oxo-2H-1-benzopyran-7,8-diyl bis(phenylcarbamate) (XIV): Yield $74 \%$ m.p. 226-227 ${ }^{\circ} \mathrm{C}$. IR (nujol, $\left.v_{\max }, \mathrm{cm}^{-1}\right)$ : $3392(\mathrm{NH}), 1695(\mathrm{NH}-\mathrm{CO}), 1670(\mathrm{C}=\mathrm{O}) .{ }^{1} \mathrm{H}$ NMR (400 MHz, DMSO- $\left.d_{6}\right): 2.39$ (s, 3프, $\left.\mathrm{C}_{4}-\underline{\mathrm{C}}_{3}\right) ; 5.88$ (s, $\underline{1} \underline{\mathrm{H}}, \mathrm{C}_{3^{-}}$

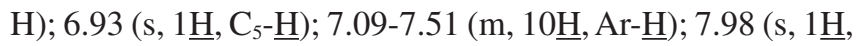
$\mathrm{NH}$ ). Analysis found: $\mathrm{C}, 66.47 ; \mathrm{H}, 4.20 ; \mathrm{N}, 6.36 \% . \mathrm{C}_{24} \mathrm{H}_{18} \mathrm{~N}_{2} \mathrm{O}_{6}$ Required: C, 66.97; H, 4.22; N, $6.51 \%$.

6-Chloro-4-methyl-2-oxo-2H-1-benzopyran-7-yl phenylcarbamate (XV): Yield $78 \%$, m.p. 268-269 ${ }^{\circ} \mathrm{C}$. IR (nujol, $\left.v_{\max }, \mathrm{cm}^{-1}\right): 3400(\mathrm{NH}), 1700(\mathrm{NH}-\mathrm{CO}), 1668(\mathrm{C}=\mathrm{O})$, 754 (C-Cl). ${ }^{1} \mathrm{H}$ NMR (400 MHz, DMSO- $\left.d_{6}\right): 2.36$ (s, 3프, $\mathrm{C}_{4-}$

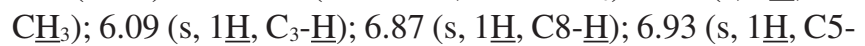
$\underline{\mathrm{H}}) ; 6.96-7.59$ (m, $\underline{\mathrm{H}}, \mathrm{Ar}-\underline{\mathrm{H}}) ; 8.55$ (s, $1 \underline{\mathrm{H}}, \mathrm{N} \underline{\mathrm{H}})$. Analysis found: $\mathrm{C}, 61.71 ; \mathrm{H}, 3.66 ; \mathrm{N}, 4.27 \% . \mathrm{C}_{17} \mathrm{H}_{12} \mathrm{NO}_{4} \mathrm{Cl}$ Required: C, 61.92; $\mathrm{H}, 3.67 ; \mathrm{N}, 4.25 \%$.

2-Oxo-2H-1-benzopyran-4-yl phenylcarbamate (XVI): Yield $80 \%$, m.p. $187-188^{\circ} \mathrm{C}$. IR (nujol, $v_{\max }, \mathrm{cm}^{-1}$ ): $3380(\mathrm{NH})$, 1710 (NH-CO), $1695(\mathrm{C}=\mathrm{O})$. Analysis found: $\mathrm{C}, 68.28 ; \mathrm{H}$, $3.69 ; \mathrm{N}, 4.94 \% . \mathrm{C}_{16} \mathrm{H}_{11} \mathrm{NO}_{4}$ Required : C, 68.32; H, 3.94; N, $4.98 \%$.

Nematicidal bioevaluation: The plant parasitic nematode Meloidogyne javanica was used as test organism. Stock solutions of $2000 \mathrm{mg} \mathrm{L}^{-1}$ of all the compounds were prepared by dispersing these in acetone. Nematicidal activity was evaluated against second stage juveniles $\left(\mathrm{J}_{2}\right)$ of $M$. javanica. A suspension of juveniles ( $1 \mathrm{~mL})$ was poured into $5 \mathrm{~cm}$ Petri-dishes. Measured quantities of stock solution were added to these Petridishes to make final concentrations of 1000, 500, 250 and 125 $\mathrm{ppm}$. Acetone and water were used as control. Each treatment was replicated three times. These Petri-dishes were kept in BOD incubator at $28 \pm 1^{\circ} \mathrm{C}$. Observations were recorded after $24 \mathrm{~h}$ and $48 \mathrm{~h}$ by counting live (active) and dead (inactive) $\mathrm{J}_{2} \mathrm{~S}$ under a stereoscopic binocular microscope and the per cent mortality was counted ${ }^{16}$. The revival of immobilized nematodes was examined by randomly transferring ten $\mathrm{J}_{2} \mathrm{~S}$ to water for 24 $\mathrm{h}$. None of those immobilized $\mathrm{J}_{2} \mathrm{~S}$ revived. The experimental data was statistically analyzed using two factorial completely randomized design; the compounds and the concentrations constituting the two factors.

\section{RESULTS AND DISCUSSION}

Pechmann condensation of orcinol (I), resorcinol (II), pyrogallol (III) and 4-chlororesorcinol (IV) with benzyl acetoacetate (V), gave their corresponding 7-hydroxy-4, 5dimethyl-2H-1-benzopyran-2-one (VI), 7-hydroxy-4-methyl2H-1-benzopyran-2-one (VII), 7, 8-dihydroxy-4-methyl-2H1-benzopyran-2-one (VIII) and 6-chloro-7-hydroxy-4-methyl2H-1-benzopyran-2-one (IX) (Scheme-I).

Their ${ }^{1} \mathrm{H}$ NMR spectra were in accordance with the proposed structures. In the spectrum $(400 \mathrm{MHz})$ of 7-hydroxy4-methyl-2H-1-benzopyran-2-one (VII), the diagnostic proton 


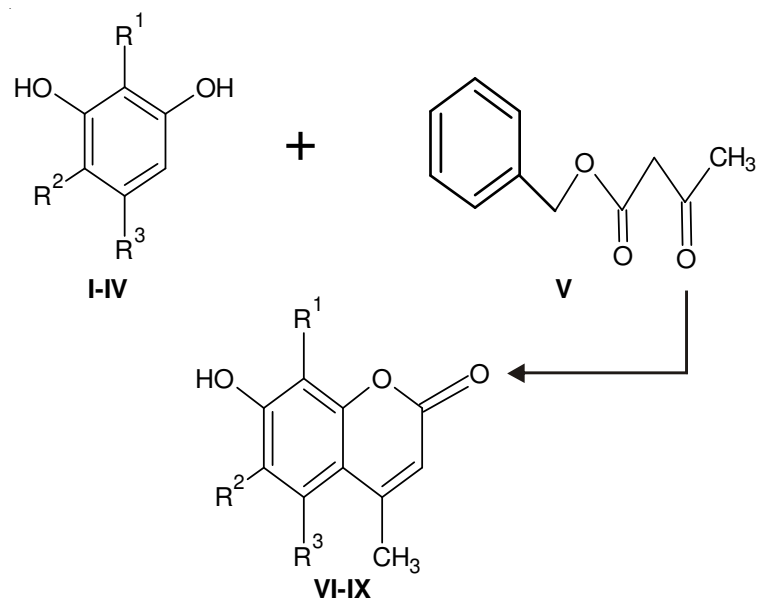

Reagents and reaction conditions

$\mathrm{H}_{2} \mathrm{SO}_{4}(73 \%)$, Stirring

\begin{tabular}{|cccc|}
\hline Compound no. & $\mathbf{R}^{1}$ & $\mathbf{R}^{2}$ & $\mathbf{R}^{3}$ \\
I, VI & $\mathrm{H}$ & $\mathrm{H}$ & $\mathrm{CH}_{3}$ \\
II, VII & $\mathrm{H}$ & $\mathrm{H}$ & $\mathrm{H}$ \\
III, VIII & $\mathrm{OH}$ & $\mathrm{H}$ & $\mathrm{H}$ \\
IV, IX & $\mathrm{H}$ & $\mathrm{Cl}$ & $\mathrm{H}$ \\
\hline
\end{tabular}

Scheme I: Synthesis of various substituted $2 H$-1-benzopyran-2-one at position 3 appeared as singlet at $6.03 \delta$. A clean singlet of $\mathrm{C}_{4}-\mathrm{CH}_{3}$ was appeared at $2.38 \delta$ followed by another singlet at $6.71 \delta$ of $\mathrm{C}_{8}$ position proton. Two aromatic protons $\mathrm{C}_{5}-\underline{\mathrm{H}}$ and $\mathrm{C}_{6}-\underline{\mathrm{H}}$ appeared downfield as doublets $(J=7.0 \mathrm{~Hz})$ integrating for one proton each at $6.80 \delta$ and $7.48 \delta$ respectively. Similarly ${ }^{1} \mathrm{H}$ NMR spectra of 7-hydroxy-4,5-dimethoxy-2H-1-benzopyran-2-one (VI) showed two singlets at $2.28 \delta$ and $2.56 \delta$ for $\mathrm{C}_{4}-\mathrm{CH}_{3}$ and $\mathrm{C}_{5}-\mathrm{CH}_{3}$ moiety along with other protons at their usual positions. The presence of a peak about $3400 \mathrm{~cm}^{-1}$ for hydroxyl group and about $1700 \mathrm{~cm}^{-1}$ for coumarin moiety in its IR spectrum further corroborated the assigned structure.

In view of great potential in 2H-1-benzopyran-2-one and their corresponding carbamates, the condensation of VI-X with phenylisocyanate (XI) by refluxing in dry benzene afforded their corresponding 4,5-dimethyl-2-oxo- $2 \mathrm{H}$-1-benzopyran-7yl phenyl carbamate (XII), 4-methyl-2-oxo-2H-1-benzopyran7-yl phenyl carbamate (XIII), 4-methyl-2-oxo-2 $\mathrm{H}$-1-benzopyran-7,8-diyl bis-(phenylcarbamate) (XIV), 6-chloro-4methyl-2-oxo-2H-1-benzopyran-7-yl phenyl carbamate (XV) and 2-oxo-2 $\mathrm{H}$-1-benzopyran-4-yl phenyl carbamate (XVI) in good yields (Scheme-II).

In ${ }^{1} \mathrm{H}$ NMR spectrum of 4,5-dimethyl-2-oxo-2H-1-benzopyran-7-yl phenyl carbamate (XII), the two protons at position 6 and 8 appeared at $6.53 \delta$ and $6.92 \delta$ as singlets respectively. The upfield shift of $\mathrm{C}_{6}-\mathrm{H}$ proton ortho to carbamoyloxy moiety<smiles>[R]c1c(O)c([R])c2oc(=O)cc(C)c2c1[R]</smiles>

VI-IX<smiles>O=C=Nc1ccccc1</smiles>

XI<smiles>[R]c1c(OC(=O)Nc2ccccc2)c([R])c2oc(=O)cc(C)c2c1[R]</smiles>

XII- XV

\section{Reagents and reaction conditions:}

Benzene, $\triangle$

\begin{tabular}{|cccc|}
\hline Compound no. & $\mathbf{R}^{\mathbf{1}}$ & $\mathbf{R}^{\mathbf{2}}$ & $\mathbf{R}^{3}$ \\
VI, XII & $\mathrm{H}$ & $\mathrm{H}$ & $\mathrm{CH}_{3}$ \\
VII, XIII & $\mathrm{H}$ & $\mathrm{H}$ & $\mathrm{H}$ \\
VIII, & $\mathrm{OH}$ & $\mathrm{H}$ & $\mathrm{H}$ \\
IX, XV & $\mathrm{H}$ & $\mathrm{Cl}$ & $\mathrm{H}$ \\
XIV & COONH-Ph & $\mathrm{H}$ & $\mathrm{H}$ \\
\hline
\end{tabular}<smiles>O=c1cc(O)c2ccccc2o1</smiles>

$\mathbf{X}$<smiles>O=C=Nc1ccccc1</smiles>

XI<smiles>O=C(Nc1ccccc1)Oc1cc(=O)oc2ccccc12</smiles>

XVI

Reagents and reaction conditions

Benzene, $\triangle$

Scheme-II: Synthesis of various substituted 2-oxo-2H -1-benzopyran-7-yl/7,8-diyl/4-yl phenyl carbamate 
appeared to be a consequence of the shielding effect of carbamate functionality. Two singlets at $2.29 \delta$ and $2.55 \delta$ integrating for three protons each were assigned to methyl moiety at positions 4 and 5 respectively. The remaining aromatic protons were appeared as multiplet at $7.22 \delta-7.46 \delta$. The broad singlet at $8.50 \delta$ was assigned to $\mathrm{N} \underline{\mathrm{H}}$ proton of carbamoyloxy moiety. The formation of carbamates of the above compounds follow from the mode of synthesis and were supported by the appearance of bands around $3340 \mathrm{~cm}^{-1}$ for $\mathrm{NH}$ functionality and around $1710 \mathrm{~cm}^{-1}$ and $1690 \mathrm{~cm}^{-1}$ for 2-pyrone and carbamoyloxy $(\mathrm{C}=\mathrm{O})$ functionality respectively. Thus, the structures of all these compounds were fully supported by their NMR and IR spectra.

Nematicidal bioevaluation: Nematicidal activity of all the synthesized compounds was evaluated against second stage juveniles $\left(\mathrm{J}_{2}\right)$ of $M$. javanica at four different concentrations viz. 1000, 500, 250 and $125 \mathrm{ppm}$. Acetone with water was used as control. No nematode mortality was recorded in these controls and is therefore not included in the Table- 1 .

The data of nematicidal activity of various substituted $2 \mathrm{H}$ 1-benzopyran-2-one against $M$. javanica $\mathrm{J}_{2} \mathrm{~S}$ after $24 \mathrm{~h}$ is given in Table-1. The interaction of compounds and concentrations was statistically significant. Compound 6-chloro-7-hydroxy4-methyl-2H-1-benzopyran-2-one (IX) showed $100 \%$ mortality at all tested concentrations and proved to be highly nematoxic. The presence of chloro group in $2 \mathrm{H}$-1-benzopyran-2-one is highly effective and resulted in complete mortality of nematodes. Further evaluation of this compound was also done at 120, 60, 30,15 and $7.5 \mathrm{ppm}$. It has shown mortality at lowest concentration also i.e, $7.5 \mathrm{ppm}$.

So due to its significantly high nematicidal activity, this compound was found most toxic in the series, followed by compound 4-hydroxy-2H-1-benzopyran-2-one (X), which has also shown an appreciable activity of $80 \%$ at $1000 \mathrm{ppm}$. Compound 7-hydroxy-4-methyl-2H-1-benzopyran-2-one (VII) was least active in the series. Rest of the compounds was moderately active. Irrespective of compounds, concentration $1000 \mathrm{ppm}$ proved to be most toxic to nematode. Further nematicidal activity of these compounds was recorded after
$48 \mathrm{~h}$. There was an increase in activity after $48 \mathrm{~h}$, as in case of 4-hydroxy-2H-1-benzopyran-2-one (X); it increased from 80 to $90 \%$ at $1000 \mathrm{ppm}$. Similarly, there was an overall increase in the nematicidal activity of rest of the compounds. In this series, all the compounds and concentration were statistically different from one another.

Various substituted 2-oxo-2H-1-benzopyran-7-yl/7,8-diyl/ 4-yl phenyl carbamates (XII-XVI) were also tested against M. javanica at 1000, 500, 250 and 125 ppm concentrations. All of these synthesized compounds were found highly toxic with $100 \%$ mortality of nematodes at all tested concentrations. Introduction of carbamoyloxy moiety in $2 \mathrm{H}$-1-benzopyran2-one resulted into high nematicidal activity. Due to their high nematicidal activity, they were further evaluated at lower concentration viz. 120, 60, 30, 15 and $7.5 \mathrm{ppm}$ and were found active even up to $7.5 \mathrm{ppm}$. Perusal of activity data revealed that $100 \%$ mortality was found up to $7.5 \mathrm{ppm}$ concentration. Mortality was recorded after $24 \mathrm{~h}$ only because no $\mathrm{J}_{2}$ S revived after $48 \mathrm{~h}$, clearly showing the highest activity of all compounds, irrespective of compounds and concentrations. All of these synthesized compounds were most toxic to nematodes with $100 \%$ mortality at all tested concentrations. The compounds showed appreciable activity.

\section{Conclusion}

From the present studies, it may concluded that substituted $2 H$-1-benzopyrane-2-ones serve as a potential lead compounds for the synthesis of various substituted 2-oxo- $2 \mathrm{H}$-1-benzopyran-7-yl/7,8-diyl/4-yl phenyl carbamates. The synthesized carbamates have exhibited a promising nematicidal activity. Compound 6-chloro-7-hydroxy-4-methyl-2H-1-benzopyran2-one (IX) showed $100 \%$ mortality at all tested concentrations and proved to be highly nematoxic. Substituted 2-oxo-2H-1benzopyran-7-yl/7,8-diyl/4-yl phenyl carbamate (XII-XVI) compounds were found highly toxic with $100 \%$ mortality of nematodes at all tested concentrations. These compounds need further exploration for their possible use as nematicides and deserve further investigation.

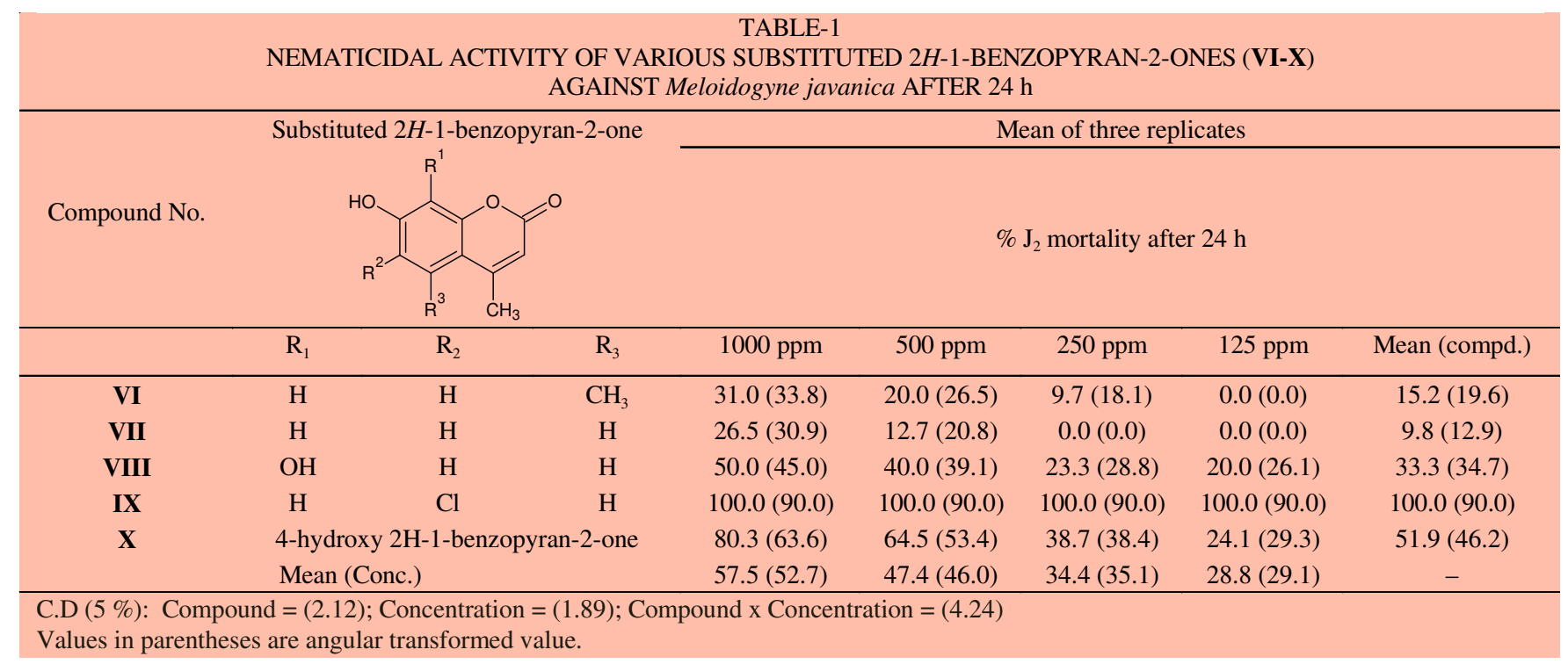




\section{ACKNOWLEDGEMENTS}

The authors are thankful to the Professor and Head, Department of Chemistry \& Physics and Department of Nematology, CCS Haryana Agricultural University, Hisar, India for providing laboratory facilities. Thanks also to SAIF, Panjab University, Chandigarh, for providing the spectral data. The financial help in the form of scholarship (POSE), received from DST, Panchkula, is thankfully acknowledged.

\section{REFERENCES}

1. P. Selvam, N. Ramlakshmi and S.K. Kumar, Int. J. Pharm. Sci. Res., 2, 413 (2011)

2. K. Takaishi, M. Izumi, N. Baba, L. Kawazu and S. Nakajima, Bioorg. Med. Chem. Lett., 18, 5614 (2008).

3. R.G. Kalkhambkar, G.M. Kulkarni, C.M. Kamanavalli, N. Premkumar, S.M.B. Asdaq and C.M. Sun, Eur. J. Med. Chem., 43, 2178 (2008).

4. R.L. Baron, Handbook of Pesticide Toxicology, Academic Press, New York, pp. 1125-1189 (1991)

5. S. Perveen, N. Fatima, K.M. Khan, A. Khan, M. Ali and M.I. Choudhary, J. Chem. Soc. Pak., 32, 338 (2010).
6. J. Yoshida, S. Kuroiwa, M. Sasaki and F. Hirata, Nippon Kagakkai Koenyokoshu, 82, 188 (2002).

7. T.W. Greene and P.G.M. Wuts, Protective Groups in Organic Synthesis, Wiley \& Sons. New York, pp. 309-348 (1991).

8. J.R. Corbett, K. Wright and A.C. Baillie, The Biochemical Mode of Action of Pesticides, Academic Press, London, edn 2, pp. 382 (1984).

9. R. Singh, T. Batra, M.S. Malik and O.P. Malik, Chim. Acta Turc., 23, 103 (1995).

10. I. Chopra, R.K. Walia and R. Singh, Pestic. Res. J., 18, 124 (2006).

11. R. Singh, B.B. Gupta, O.P. Malik and H.R. Kataria, Pestic. Sci., 20, 125 (1987).

12. K.M. Khan, Z.S. Saify, S. Begum, F. Noor, M.Z. Khan, S. Hayat, M.I. Choudhary, S. Perveen, Atta-Ur-Rahman and Zia-Ullah, Nat. Prod. Res., 17, 115 (2003).

13. B.S. Furniss, A.J. Hannaford, V. Rogers, P.W. Smith and A.R. Tatchell, Text Book of Practical Organic Chemistry (Vogel), Great Britain ELBS and Longmann, edn 4, p. 925 (1978).

14. E.V. Stoyanov and J. Mezger, Molecules, 10, 762 (2005).

15. S.J. Park, J.C. Lee and K.I. Lee, Bull. Korean Chem. Soc., 28, 1203 (2007).

16. K. Gill, S.K. Mehta, M.S. Malik, O.P. Malik and R.K. Walia, Nematol. Mediterr., 29, 219 (2001). 